\title{
Characteristics of the equatorial electrojet current in the central region of South America
}

\author{
R. G. Rastogi ${ }^{1}$, H. Chandra ${ }^{1}$, M. E. James ${ }^{2}$, K. Kitamura ${ }^{3}$, and K. Yumoto ${ }^{4}$ \\ ${ }^{1}$ Physical Research Laboratory, Ahmedabad 380009, India \\ ${ }^{2}$ Department of Physics, Gujarat University, Ahmedabad 380 009, India \\ ${ }^{3}$ Tokuyama College of Technology, Shunan, Yamaguchi 745-8585, Japan \\ ${ }^{4}$ Space Environment Research Center, Kyushu University, Fukuoka, Japan
}

(Received October 8, 2007; Revised January 28, 2008; Accepted February 18, 2008; Online published July 4, 2008)

\begin{abstract}
We describe here for the first time the morphology of the equatorial electrojet (EEJ) in the Central American Sector based on an analysis of the geomagnetic field components from six stations distributed on both sides of the dip equator along the $60^{\circ} \mathrm{W}$ geographic longitude sector. Diurnal and latitudinal variations in the horizontal and vertical components are shown to follow the Chapman model of EEJ. The horizontal component vector due to the ionospheric current aligned itself close to magnetic north, with a mean Declination of $10^{\circ} \mathrm{W}$ (ranging from $9^{\circ} \mathrm{W}$ to $14^{\circ} \mathrm{W}$ ). There was a significant counter-electrojet effect before sunrise at stations close to the dip equator, suggesting late reversal of solar-quiet $\left(S_{\mathrm{q}}\right)$ electric field in the morning hours. The observed variations in the magnetic meridional current did not seem to be associated with EEJ currents. The centre of the electrojet was around $0.25^{\circ} \mathrm{S}$ of the dip equator in the morning hours and shifted gradually to $1.5^{\circ} \mathrm{S}$ by the evening hours. Magnetic storms occurring during the midday hours produced an exceptionally large decrease in the $H$ (horizontal component) field at stations close to the dip equator.
\end{abstract}

Key words: Equatorial electrojet, magnetic storm effects, abnormal large Declination region, dip equator in Central American Sector, sunrise counter-electrojet.

\section{Theme of the Paper}

It would be useful to define the various mean magnetic field components used in the paper. These are (1) $H$ (in nT), the scalar value of the horizontal component, (2) $Z$ (nT), the vertical component pointing downward, (3) $D^{\circ}$, the Declination, which is the deviation of the magnetic meridian from the geographic meridian; it is a positive value if the shift is east of geographic north, (4) $X$ (nT), which is the horizontal component pointing to the geographic north and equal to $H \cos D$, (5) $Y$ (nT), which is the eastward component pointing to geographic east and equal to $H \sin D$, (6) $I^{\circ}$, which is the inclination of the magnetic field lines from the horizontal (positive, pointing downwards); it is equal to $\tan ^{-1}(Z / H)$. These magnetic field components are the result of sources inside the solid Earth in the region. There are also currents outside the solid Earth causing regular solar daily variations in the magnetic field components; these are designated as $\Delta H, \Delta Y$ and $\Delta Z$ and are computed as the deviation of the component at any time $t$ of the day with respect to the corresponding value at the preceding midnight. These components define the electric currents in the ionosphere and magnetosphere together with their induced parts in the conducting regions inside the solid Earth.

The main theme of the paper is to identify if the ionospheric currents that affect the diurnal variations of the

Copyright (c) The Society of Geomagnetism and Earth, Planetary and Space Sciences (SGEPSS); The Seismological Society of Japan; The Volcanological Society of Japan; The Geodetic Society of Japan; The Japanese Society for Planetary Sciences; TERRAPUB. mean magnetic field in this $60^{\circ} \mathrm{W}$ geographic region. $\Delta H$ is the perturbation component and defined as

$$
H=H_{\mathrm{o}}+\Delta H
$$

where $H_{\mathrm{o}}$ is the base value of the $H$ component. The outputs of the magnetometers are

$$
\begin{aligned}
B_{H} & =B_{H_{\mathrm{o}}}+\Delta B_{H} \\
B_{Y} & =B_{Y_{\mathrm{o}}}+\Delta B_{Y}
\end{aligned}
$$

Where $B_{H_{\mathrm{o}}}$ and $B_{Y_{\mathrm{o}}}$ are the base values of the $B_{H}$, (magnetic north) and $B_{Y}$ (magnetic east) components. As the magnetometers were installed such as to have $B_{Y_{0}}=0$, $B_{Y}=\Delta B_{Y}$. Therefore, the $H$ component will be given by

$$
H=\left[\left(B_{H_{0}}+\Delta B_{H}\right)^{2}+\left(\Delta B_{Y}\right)^{2}\right]^{\frac{1}{2}}
$$

Since the horizontal field values of the stations as listed in Table 1 are about 25,000 nT, which is more than 200-fold greater than the daily ranges of the $H$ component due to the solar-quiet $\left(S_{\mathrm{q}}\right)$ variation, we can assume that $H_{\mathrm{o}}$ is almost same as the $H$ field values given in Table 1 and also the same as $B_{H_{0}}$. With this assumption Eq. (D) becomes

$$
H=\left[\left(H_{\mathrm{o}}+\Delta B_{H}\right)^{2}+\left(\Delta B_{Y}\right)^{2}\right]^{\frac{1}{2}}
$$

As the ratio between the absolute value of the $H$ component and the daily range of $B_{Y}$ is less than 0.001 , we can neglect $\Delta B_{Y}$ in Eq. (E) and therefore

$$
H=H_{\mathrm{o}}+\Delta B_{H}
$$


Table 1. Coordinates of stations used: IGRF Year Sep-Oct 1994.

\begin{tabular}{|c|c|c|c|c|c|c|}
\hline $\begin{array}{l}\text { Station name } \\
\text { Station code }\end{array}$ & $\begin{array}{l}\text { Porto Velho } \\
\text { POV }\end{array}$ & $\begin{array}{c}\text { Ariquemes } \\
\text { ARI }\end{array}$ & $\begin{array}{c}\text { Presidente Medici } \\
\text { PRM }\end{array}$ & $\begin{array}{l}\text { Vilhena } \\
\text { VIL }\end{array}$ & $\begin{array}{l}\text { Colibri } \\
\text { CLB }\end{array}$ & $\begin{array}{c}\text { Cuiaba } \\
\text { CUI }\end{array}$ \\
\hline Geog. Lat $\left({ }^{\circ} \mathrm{S}\right)$ & 8.80 & 9.56 & 11.20 & 12.72 & 13.70 & 15.35 \\
\hline Geog. Long $\left({ }^{\circ} \mathrm{W}\right)$ & 63.90 & 63.04 & 61.80 & 60.13 & 59.80 & 56.05 \\
\hline Horizontal field, $H(\mathrm{nT})$ & 25998 & 25761 & 25264 & 24727 & 24429 & 23614 \\
\hline Declination $\left({ }^{\circ} \mathrm{E}\right)$ & -8.95 & -9.48 & -10.14 & -11.16 & -11.23 & -13.79 \\
\hline Vertical field (nT) & 2607 & 1777 & 150 & -1448 & -2264 & -4486 \\
\hline$X$ field (nT) & 25682 & 25410 & 24870 & 24260 & 23961 & 22933 \\
\hline$Y$ field (nT) & -4043 & -4241 & -4448 & -4786 & -4759 & -5630 \\
\hline Inclination $\left({ }^{\circ} \mathrm{N}\right)$ & 5.73 & 3.95 & 0.34 & -3.35 & -5.30 & -10.76 \\
\hline Daily range in $B_{H}(\mathrm{nT})$ & 80 & 90 & 100 & 93 & 83 & 58 \\
\hline Daily range in $B_{Y}(\mathrm{nT})$ & 7 & 8 & 10 & 10 & 10 & 21 \\
\hline Daily range in $Z$ (nT) & -36 & -26 & -6 & 15 & 30 & 21 \\
\hline
\end{tabular}

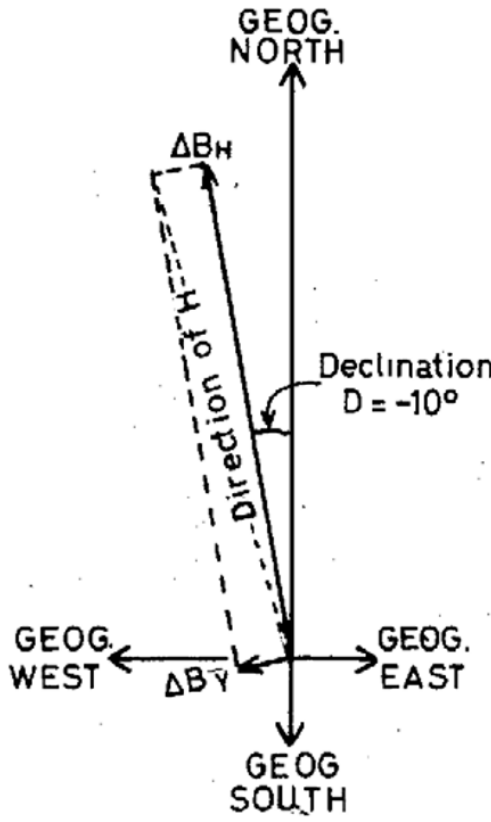

$\Delta \mathrm{X}=\Delta \mathrm{B}_{\mathrm{H}} \cos (\mathrm{D})+\Delta \mathrm{B}_{\mathrm{Y}} \sin (\mathrm{D})$ $\Delta \mathrm{Y}=\Delta \mathrm{B}_{\mathrm{H}} \sin (\mathrm{D})+\Delta \mathrm{B}_{\mathrm{Y}} \cos (\mathrm{D})$

Fig. 1. Geometry showing the relationship between the $B_{H}$ and $B_{Y}$ components measured by fluxgate coils and the IAGA defined $X$ and $Y$ components.

A comparison of Eq. (A) with Eq. (F) shows that $\Delta B_{H}$ is almost same as $\Delta H$. In terms of the Declination, the $\Delta X, \Delta Y$ components can be determined from the following equation,

$$
\begin{aligned}
\Delta X & =\Delta B_{H} \cos (D)+\Delta B_{Y} \sin (D) \\
\Delta Y & =\Delta B_{H} \sin (D)+\Delta B_{Y} \cos (D)
\end{aligned}
$$

Figure 1 shows the relationship between the $B_{H}$ and $B_{Y}$ components measured by the fluxgate coils and the general International Association of Geomagnetism and Aeronomy (IAGA) defined parameters $X$ and $Y$ components. The $\Delta B_{H}$ and $\Delta B_{Y}$ components are normal to each other; therefore, the magnitude of horizontal field component, $\Delta H$, would be $\left[\Delta B_{H}^{2}+\Delta B_{Y}^{2}\right]^{1 / 2}$ and its direction $(\delta)$ would be $\arctan ^{-1}\left(\Delta B_{H} / \Delta B_{Y}\right)$ with respect to the magnetic meridian or $(\delta+D)$ with respect to the geographic meridian. The $\Delta X$ and $\Delta Y$ components would then be given as $\Delta H \sin (\delta+D)$ and $\Delta H \cos (\delta+D)$, respectively.

\section{Introduction}

Chapman (1951), in his citing of the earlier results of the latitudinal survey of the geomagnetic $H$ field in Peru by A. A. Giesecke, suggested the existence of a narrow band of eastward sheet current during the daytime hours at an altitude of the $E$ region of the ionosphere $(100 \mathrm{~km})$ within $\pm 3^{\circ}$ latitude centered over the magnetic equator. He named this band of current the equatorial electrojet (EEJ). He also formulated equations for the latitudinal variations of the northward $(X$ or $H$ ) and vertical $(Z)$ fields observed at ground level for different types of electrojet current, such as infinitely straight linear or cylindrical current, a band of uniform current and parabolically distributed current. The calculations also considered the effect of induced currents and return flow. The equations for the case of a band of uniform current of width $2 w$ (in the N-S direction) at a height $h$ are,

$$
\begin{aligned}
\Delta H & =\frac{J}{w} \tan ^{-1} \frac{2 w h}{h^{2}+x^{2}-w^{2}} \\
\Delta Z & =\frac{J}{2 w} \log \frac{(x+w)^{2}+h^{2}}{(x-w)^{2}+h^{2}}
\end{aligned}
$$

where $w$ is the semi-width of the current sheet respectively, $x$ is the distance from the magnetic equator and $J$ is the strength of the uniform EEJ current across the band.

It was assumed tacitly that the horizontal magnetic field is wholly northward and the electric field and the current entirely eastward. Thus, there would be no daily variations in the $Y$ and $Z$ fields at a station close to the centre of the electrojet current. The latitudinal variations in $H$ and $Z$ at any particular time of the day are shown in Fig. 2. $\Delta Z$ is the maximum variation at the southern edge and the minimum at the northern edge of the electrojet, with the magnitude being about 0.67 -fold that of the value of $H$ at the dip equator $\left(H_{\mathrm{o}}\right)$.

Baker and Martyn (1953) provided the first theoretical model of the electric field and currents at low latitudes. At the equator, where the electric field is eastward and 


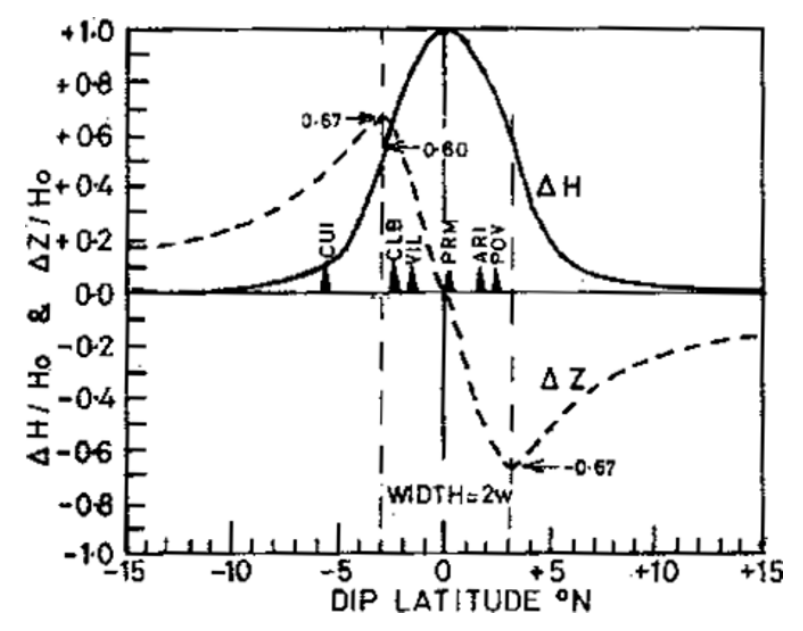

Fig. 2. The positions of the stations in Central Brazil with respect to the latitudinal variations of $\Delta H$ and $\Delta Z$ due to the equatorial electrojet current belt according to the Chapman's model (1951).

the geomagnetic field is northward, the electrons within a height region of 70-140 km drift upward relative to ions. The vertical currents are inhibited outside the boundaries of this region, and this produces the Hall polarization field. An abnormally large Cowling conductivity is thus generated close to the dip equator because of the additional eastward Hall current due to the vertical polarization field within $\pm 3^{\circ}$ dip latitudes with the same electric field system that generates the global $S_{\mathrm{q}}$ current.

During the International Geophysical Year (IGY), geomagnetic observatories were established at Addis-Ababa (AAE), Trivandrum (TRD), Koror (KOR) and Jarvis Island (JAR). The Carnegie Institution of Washington, Central Radio Propagation Laboratory, Boulder, USA and the Institute of Geophysics of Peru had already set up a very unique chain of four magnetic and ionospheric observatories in Peru, additional to the existing one at Huancayo. Forbush and Casaverde (1961) described the structure of the EEJ and the effects of sudden storm commencement (SSC), solar flare effects (sfe) and other events on the EEJ in Peru, and they estimated the center of the EEJ by the symmetry of the longitudinal variation of $\Delta H$ and by the crossing of the zero line in the latitudinal variation of $\Delta Z$. Godivier and Grenn (1965) described the electrojet variations along the $18^{\circ} \mathrm{E}$ longitude sector for the period February to July 1958. Rastogi (1962) discovered a longitudinal variation in the strength of the electrojet, with a maximum in American longitude and a minimum in Indian longitude.

Rastogi and Stening (2002) discussed the daily variations in the eastward component $Y$ (Declination) at EEJ stations during the IGY. The daily variation of $Y$ showed a daytime peak at Huancayo during any of the seasons and at Jarvis during March and October. The $Y$ field at Addis-Ababa and Trivandrum showed small variations during the day but a completely opposite character between the two solstices. No direct relation between the eastward and northward magnetic fields at the EEJ belt could be identified. Rastogi (2003) subsequently showed the existence of a single large daytime minimum of the $Y$ field at Vassouras in
South America and at M'Bour, Ibadan and Bangui in the African longitude region where the position of magnetic equator changes very sharply from southern to northern latitudes.

Fambitakoye and Mayaud (1976a, b) described the characteristics of the regular solar daily variations in the region of EEJ using the data from a chain of nine observatories distributed over $3000 \mathrm{~km}$ in Central Africa. They split the solar regular (SR) variations into two parts - one due to planetary current and other due to the narrow band current system along the dip equator.

Rigoti et al. (1999) described the characteristics of the EEJ from an array of 29 vector magnetometers in N-NE Brazil from November 1990 to March 1991. Arora et al. (1993) and Doumouya et al. (1998) described similar results for the Indian and West African region during the International Equatorial Electrojet Year 1993-1994. However, no information is currently available on the EEJ in the central region of South America. It is of great importance to study the features of the EEJ in this anomaly region to determine whether the properties of EEJ there, which have been taken to be true without any empirical evidence, are consistent with those shown for other regions.

\section{Data Analysis}

Professor Tai-ichi Kitamura initiated the installation of portable three-component digital flux gate magnetometers at a number of equatorial stations around the world; this array was developed further by Prof. K. Yumoto. Here, we describe the features of the EEJ using data obtained from a set of six observatories in the central region of Brazil. The geomagnetic field components used are $H$ (pointing to magnetic north), $Z$ (vertically downward) and $Y$ (perpendicular to $H$ and $Z$, pointing to eastward). In the absence of a precise determination of the geographic meridian at temporary field stations, one of the vertical coils of the fluxgate magnetometers was aligned along the local geomagnetic meridian when the signal from this coil was at a minimum. In his study of the electrojet in the eastern region of Brazil, Hesse (1982) denoted this field as the $B_{Y}$ field. The second vertical coil would give a signal proportional to the horizontal field component in the fixed direction along the magnetic meridian and is not the horizontal field $H$ defined by the IAGA rules. We denote this field as the $B_{H}$ field. As shown later these $B_{H}$ and $B_{Y}$ fields can be converted into the standardly accepted $X$ or $Y$ components.

Figure 3 shows the contours of constant Declination in central and eastern Brazil as well as the locations of the magnetic stations organized by the Space Environment Research Center of Kyushu University, Fukuoka, Japan. It should be noted that the Declination in Brazil varies from $6^{\circ} \mathrm{W}$ to $23^{\circ} \mathrm{W}$. The magnetic meridian therefore has a larger deviation from the geographic meridian than anywhere else in the world. The sites of the stations were distributed along the two longitude sectors, with one chain spread out from $65^{\circ} \mathrm{W}$ to $55^{\circ} \mathrm{W}$ geographic longitudes, with declinations varying between $7^{\circ}$ and $13^{\circ} \mathrm{W}$, and the second chain spread out between $18^{\circ} \mathrm{W}$ and $23^{\circ} \mathrm{W}$ geographic longitudes, with declinations varying between $19^{\circ} \mathrm{W}$ and $22^{\circ} \mathrm{W}$. The stations in both chains were spread out along both sides of the mag- 


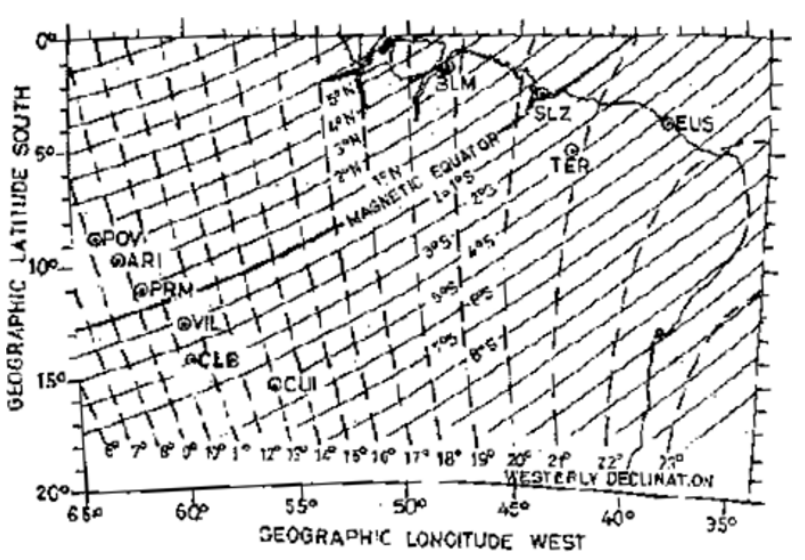

Fig. 3. Contours of constant declination and inclination in central and eastern Brazil. The chain of stations of Kyushu University are also marked.

netic equator.

The geographic and geomagnetic parameters of the stations are given in Table 1, and the position of these stations with respect to a standard latitudinal profile of $\Delta H$ and $\Delta Z$ in the electrojet belt is shown in Fig. 2. The geomagnetic parameters are calculated using the International Geomagnetic Reference Field (IGRF) corrected for the period concerned. It can be seen that the station PRM (Presidente Medici, Inclination $\left.I=0.34^{\circ} \mathrm{N}\right)$ was closest to the dip equator. The stations ARI (Ariquemes, $I=3.95^{\circ} \mathrm{N}$ ) and POV (Porto Velho, $I=5.73^{\circ} \mathrm{N}$ ) were situated in the northern part of EEJ, while the stations VIL (Vilhena, $I=$ $3.35^{\circ} \mathrm{S}$ ) and CLB (Colibri, $I=5.30^{\circ} \mathrm{S}$ ) were within the southern part of EEJ. Station CUI (Cuiaba, $I=10.76^{\circ} \mathrm{S}$ ) was outside the EEJ belt. The geographic longitudes of the stations ranged between $56^{\circ} \mathrm{W}$ and $64^{\circ} \mathrm{W}$; therefore, the local time was used, corresponding to $60^{\circ} \mathrm{W}$ (UT minus $4 \mathrm{~h}$ ). It may be noted that the Declination at these stations ranged from about $9^{\circ} \mathrm{W}$ at POV to $14^{\circ} \mathrm{W}$ at CUI. All of these stations were well inland, far from any ocean or mountain range; we therefore did not expect any influence from abnormal induction currents due to the conductivity contrasts.

Figure 4 provides an overview of the daily variations of the $B_{H}, B_{Y}$ and $Z$ components, reproduced from stacks of curves for all the six stations downloaded from the website of the Kyushu University for the dates 21 September to 30 September 1994. We must stress that all the curves have the same uniform scale for a proper comparison between different components; the local time of the curves are in universal time and so the local noon would correspond to 1600 UT.

The daily variations in $B_{H}$ show a maximum around local midday at any of the stations. The day-to-day variations and even the minor fluctuations are faithfully reproduced at all stations. On average, the magnitude of daily variation seems to be largest at PRM, which was closest to the magnetic equator.

For the variations in the $Z$ component, the stations POV and ARI in the northern side of the dip equator show a large minimum during the noon hours. Station PRM shows

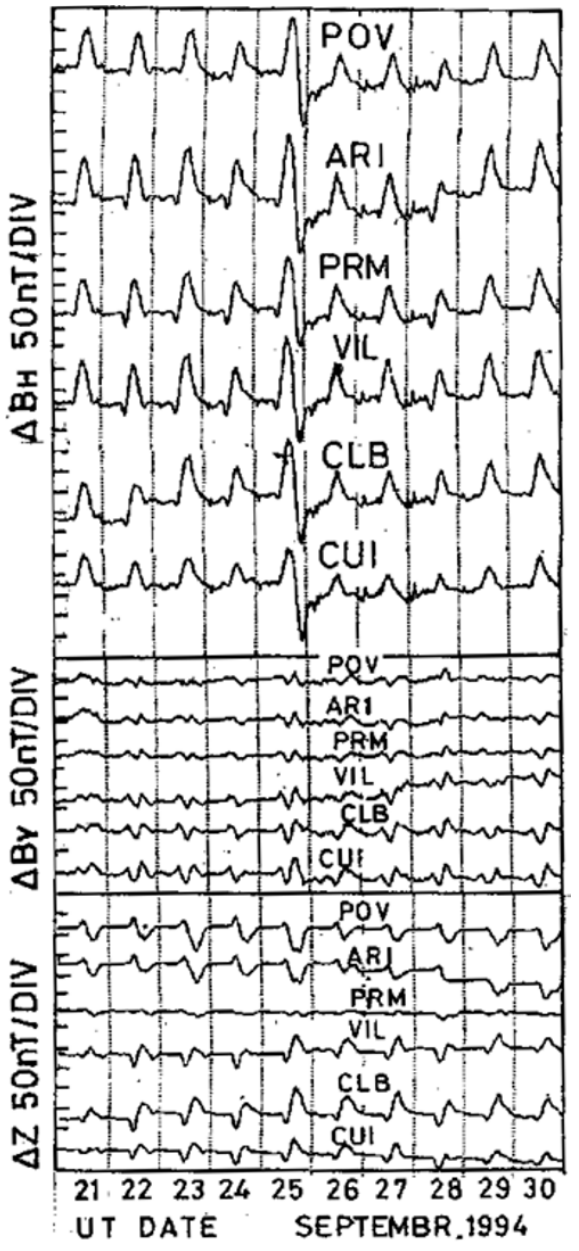

Fig. 4. Daily variations in $B_{H}, B_{Y}$ and $Z$ for all the six stations in central Brazil for the period 21 to 30 September 1994.

the least daily variation, while VIL, south of dip equator, shows positive deviations during midday. The daily peaks of $\Delta Z$ are the largest at CLB, which is at a latitude close to the southern edge of the electrojet belt. At CUI, which is located outside of the EEJ belt, there is no observable consistent daily variation in $\Delta Z$.

The daily variation in the $B_{Y}$ component at any one station does not seem to be consistent from one day to another, but on a particular day the variations are remarkably similar at all stations even on very minute detail. The magnitude of the variation is largest at the southernmost station CUI.

The original data are in 3-s interval series. These were grouped into hourly intervals. Kentarou Kitamura computed hourly mean values of $B_{H}, B_{Y}$ and $Z$ (starting from hourly interval $0000 \mathrm{UT}$ and going to $0100 \mathrm{UT}$; hence, hourly mean values refer to ( $0.5 \mathrm{~h} \mathrm{UT,} 1.5 \mathrm{~h} \mathrm{UT}$ and so on). Simultaneous data from all the six stations were available only for the months of September and October 1994; consequently, only this period was used for the present analysis. The tables presenting the data in the daily series in UT were first converted into daily series in local time. The 0.5 LT value was then taken as the base line value and subtracted from the data for each other hour on that particular day; in this manner, we obtained tables of data on local time versus local date. The Kyushu University web site provided 


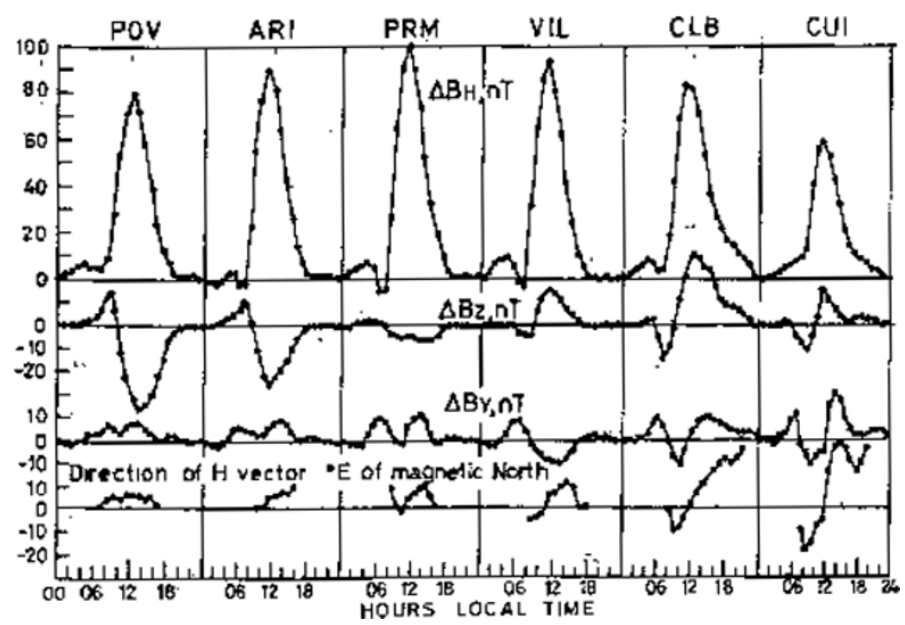

Fig. 5. Mean daily variations of $\Delta B_{H}, \Delta B_{Y}$ and $\Delta Z$ averaged for September and October 1994 at each of the six geomagnetic observatories in Central Brazil.

the quick look plots of the daily variations of $B_{H}, B_{Y}$ and $Z$ for each month for all stations. The digital data tables were compared with corresponding daily plots of the data. Any daily series with a break of data or a sudden shift in the base value of the data was deleted. Thus, only complete daily series were used in the computations. The average daily variations on five International quiet days of September and October 1994 were computed for the $B_{H}, B_{Y}$ and $Z$ components for all six stations, and these formed the basis for further analysis.

\section{Results}

\section{1 $S_{\mathrm{q}}$ variations of $B_{H}, B_{Y}$ and $Z$}

The $S_{\mathrm{q}}$ variations of $B_{H}, B_{Y}$ and $Z$ averaged for September-October 1994 at each of the stations are shown in Fig. 5. $\Delta B_{H}$ showed a maximum just before noon at all of the stations, with the magnitude of $\Delta B_{H}$ largest at PRM, the station nearest to the dip equator, and progressively decreasing at stations north and south of PRM. The hourly values of $\Delta B_{H}$ were seen to start increasing steadily from the midnight hours onwards at all of the stations. A significant dip in $\Delta B_{H}$ was seen around the sunrise hours; this dip was most prominently at PRM and decreased in magnitude at stations farther from the equator. At CLB and CUI, $\Delta B_{H}$ continued to steadily decrease from the midday hours onwards to the midnight hours. Rastogi and Iyer (1976) detected this feature of $S_{\mathrm{q}} H$ for the EEJ station Kodaikanal during each of the months of the maximum sunspot years. An explanation for this anomaly needs further study, but it may be associated with the abnormally low magnetic field at the middle latitudes in South America.

Stations POV and ARI, which are situated near the northern edge of the EEJ, showed a large minimum of $\Delta Z$ around noon at all of the stations. Station CLB, which is near the southern fringe of EEJ, showed a midday maximum of $\Delta Z$. The zero $\Delta Z$ occurred about $0.5^{\circ}$ south of PRM. Sunrise peaks in $\Delta Z$ were indicated at all stations to correspond to the minima of $\Delta H$ at the same time, thereby confirming the phenomenon to a westward ionospheric current at sunrise hours.

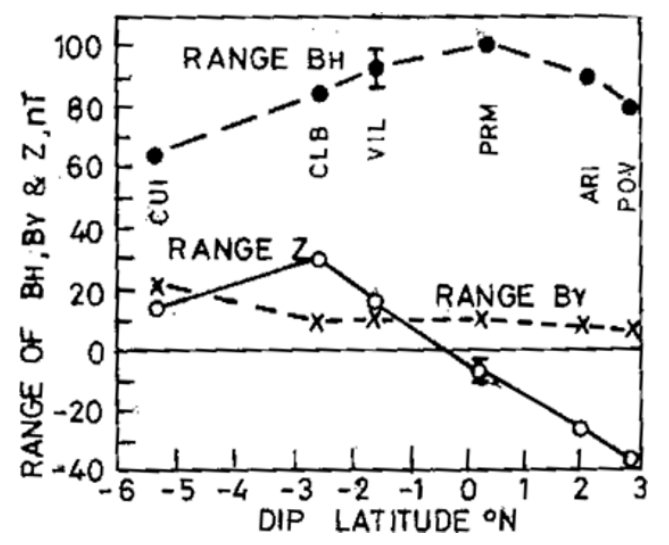

Fig. 6. Variations of the daily ranges of $B_{H}, B_{Y}$ and $Z$ fields with dip latitude for Central Brazil Sector during September-October 1994.

In terms of the variation in $S_{\mathrm{q}}$ in the eastward field $\left(\Delta B_{Y}\right)$, a depression around the midday hours was observed at all stations, with a negative value at some stations. Basically, no significant latitudinal variation in the range of $\Delta B_{Y}$ was seen, suggesting that the meridional current is rather independent of the zonal current in this region.

The variations in the mean daily ranges of the $B_{H}, B_{Y}$ and $Z$ fields, together with dip latitude, for the Central Brazil Sector during September-October 1994 are shown in Fig. 6. The errors in the mean of $\Delta B_{H}$ and $\Delta Z$ at $12 \mathrm{~h} \mathrm{LT}$ at PRM, situated near the center of electrojet, and at POV, situated near the edge of the electrojet, are also indicated in the figure. The error in the mean is $5.3 \mathrm{nT}$ for $\Delta B_{H}$ and $5.6 \mathrm{nT}$ for $\Delta Z$ at POV and $8.6 \mathrm{nT}$ for $\Delta B_{H}$ and $2.9 \mathrm{nT}$ for $\Delta Z$ at PRM. The daily range in $B_{H}$ varies from about $60 \mathrm{nT}$ outside the electrojet belt to about $90 \mathrm{nT}$ at PRM near the electrojet centre. Thus, the electrojet component of the ionospheric current is only about $30 \mathrm{nT}$ compared to $60 \mathrm{nT}$ for the planetary component. The range of $Z$ varies from about 20-30 nT at the southern edge of the electrojet to $-40 \mathrm{nT}$ at the northern edge. It is interesting to note 

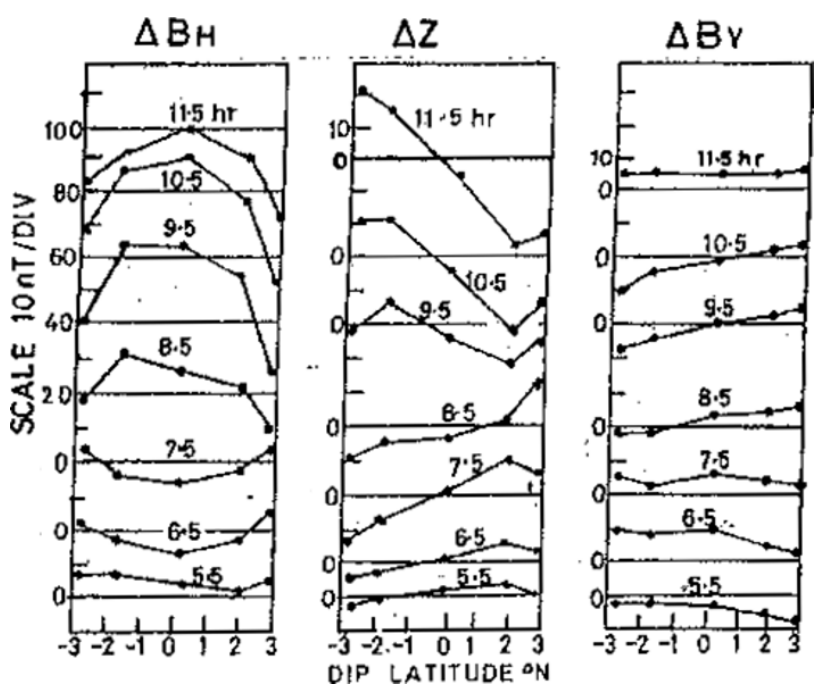

Fig. 7. Dip latitude variations in the $\Delta B_{H}, \Delta B_{Y}$ and $\Delta Z$ in the Central Brazil Sector at fixed local hours 0.5 to 11.5 averaged over September-October 1994.

that $\Delta Z$ becomes zero at about half a degree south of dip equator. The error in the mean is only about $3 \mathrm{nT}$ near the center of electrojet. We therefore conclude that the centre of the electrojet is definitely located south of the dip equator. There is no significant latitudinal variation in the range of $\Delta B_{Y}$.

\subsection{Diurnal development of $\Delta B_{H}, \Delta Z$ and $\Delta B_{Y}$}

Figure 7 shows the latitudinal variations of $\Delta B_{H}, \Delta B_{Y}$ and $\Delta Z$ during different local hours $(5.5-11.5 \mathrm{~h})$ averaged for September and October 1994. At 5.5 LT, before sunrise, there was no latitudinal variation, with $\Delta B_{H}$ being around $5 \mathrm{nT}$, suggesting a nighttime condition. At $6.5 \mathrm{LT}$, when the sunrise had generated fresh $E$ region ionizations, the latitudinal variation of $\Delta B_{H}$ showed a distinct minimum of about $5 \mathrm{nT}$ at the centre and about $10 \mathrm{nT}$ at the edges of the EEJ belt. A similar condition prevailed at 7.5 LT. This result suggests that the E-W electric field reversed at these longitude sectors about $2 \mathrm{~h}$ after sunrise, producing sunrise counter-electrojet events. The normal electrojet had developed at 8.5 LT and increased its magnitude thereafter up to $11.5 \mathrm{LT}$.

In terms of the variations in $\Delta Z$, the latitudinal variation showed a maximum around the northern edge and negative values at the southern edge of the EEJ belt between the period 5.5 to $8.5 \mathrm{LT}$, thereby confirming the presence of the counter-electrojet current during these hours. The negative $\Delta Z$ at the northern edge and positive $\Delta Z$ at the southern edge of the EEJ belt, characteristic of the normal electrojet, was only observed at $9.5 \mathrm{LT}$.

Latitudinal variations in $\Delta B_{Y}$ did not show any special feature, except of a slow gradient within -3 to $+3^{\circ}$ dip latitudes.

\subsection{Diurnal development of $\Delta B_{H}$ versus $\Delta B_{Y}$ and $\Delta B_{H}$ versus $\Delta Z$ current loops}

The orthogonality of the magnetic northward component of the magnetic field $(H)$ and the eastward electric field $(E)$ at the base of the ionospheric $E$ region causes a vertical upward polarization electric field due to the inhibition of current. This polarization field produces abnormally large Cowling conductivity in the direction of the primary electric field. Thus, the normal EEJ is generally assumed to be flowing eastward, normal to the direction of the horizontal magnetic field $H$, i.e. in the direction of Declination.

Figure 8(a) shows the direction of the horizontal current vectors at different times of the day at each of the stations in the Central Brazil area. The Declination values range from $9.0^{\circ} \mathrm{W}$ at $\mathrm{POV}$ to $13.8^{\circ} \mathrm{W}$ at CUI. It can be seen that the $\Delta B_{H}$ and $\Delta B_{Y}$ loops for any of the stations were symmetrical along the magnetic north direction. The loop was narrowest for the northernmost station, POV, and widened steadily towards the southern stations. Thus, the meridional current at the southernmost stations in Latin America was widely spread in direction, narrowing up towards the magnetic north at stations closer to the equator. The usual morning minimum and afternoon maximum typical of the southern hemisphere $\Delta Y$ were observed at the southernmost station. Thus, it is interesting to note that at least in the $60^{\circ} \mathrm{W}$ longitude sector the midday EEJ current flows fairly constantly in the magnetic eastward direction despite the abnormally large westerly Declination. At stations outside of the EEJ belt, the $S_{\mathrm{q}} Y$ is affected by the mid-latitude $S_{\mathrm{q}}$ current system.

Figure $8(\mathrm{~b})$ shows the variations in the direction of the $\Delta B_{H}$ and $\Delta Z$ vectors in the meridional plane during the course of the day averaged for September and October 1994 for each of the stations. At PRM, the station close to the dip equator, the loop is very narrow and precisely oriented in the N-S direction. At VIL $\left(I=3.4^{\circ} \mathrm{S}\right)$, the loop is slightly broader than at PRM and is tilted towards positive $Z$ (i.e. downward); at ARI $\left(I=4^{\circ} \mathrm{N}\right)$, the loop is tilted towards negative $Z$ (i.e. upward); at CLB $\left(I=5^{\circ} \mathrm{S}\right)$ and POV $\left(I=5.7^{\circ} \mathrm{N}\right)$, stations near the edges of the electrojet belt, the loops are broader than that at any other stations.

\subsection{Seasonal variation in the equatorial electrojet}

Data at some of the stations were available for the period September to December 1994. Figure 9 shows the monthly average $S_{\mathrm{q}}$ variation of $B_{H}$ at the equatorial station PRM and at POV, a station close to the northern edge of the EEJ. $S_{\mathrm{q}}$ variations of the $Z$ component were also found at the northern and southern fringe stations VIL and ARI. The daily range of $B_{H}$ was clearly at a maximum at both these stations during the month of October 1994 and was much reduced in November and December 1994. This confirms the conclusion drawn by Chapman and Rajarao (1965) on equinoctial maximum of EEJ. During the period from midnight to the sunrise, $\Delta B_{H}$ at POV showed a consistent and gradual increase, followed by a rapid increase after sunrise. $\Delta B_{H}$ at PRM, close to the dip equator, showed a minimum in the early morning hours just before the normal electrojet; this dip was most predominantly in October and showed a decreasing magnitude in September, November and December. The northern off-equator station ARI showed a corresponding minimum $\Delta Z$, and the southern off-equator station VIL showed a corresponding maximum $\Delta Z$.

\subsection{Day-to-day variations of $\Delta B_{H}, \Delta B_{Y}$ and $\Delta Z$}

We then computed the deviations of the $B_{H}, B_{Y}$ and $Z$ field at noon (1130 LT) on each day from the corresponding midnight (preceding) value for the $B_{H}, B_{Y}$ and $Z$ fields 


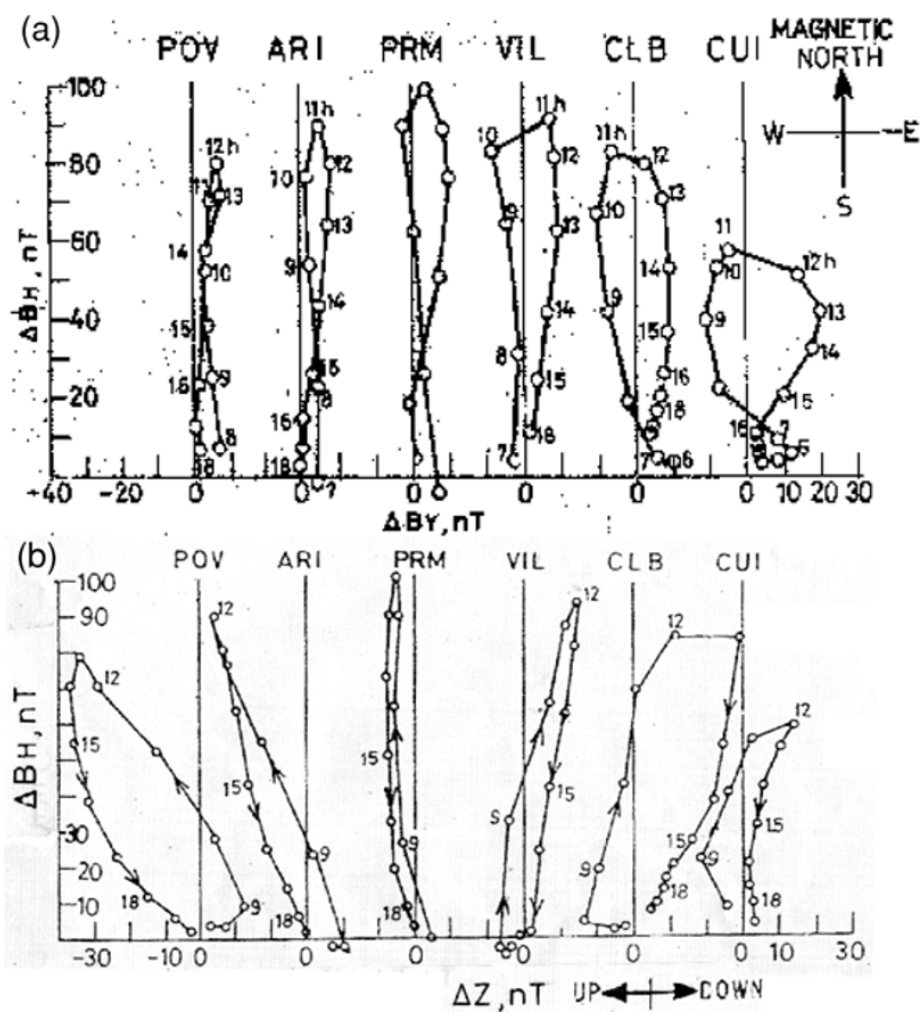

Fig. 8. (a) Daily variations of the direction of the horizontal field at different stations in Central Brazil Sector during September-October 1994. (b) Daily variations in the direction of the horizontal field in the meridional plane at different stations in Central Brazil Sector during the September-October 1994.

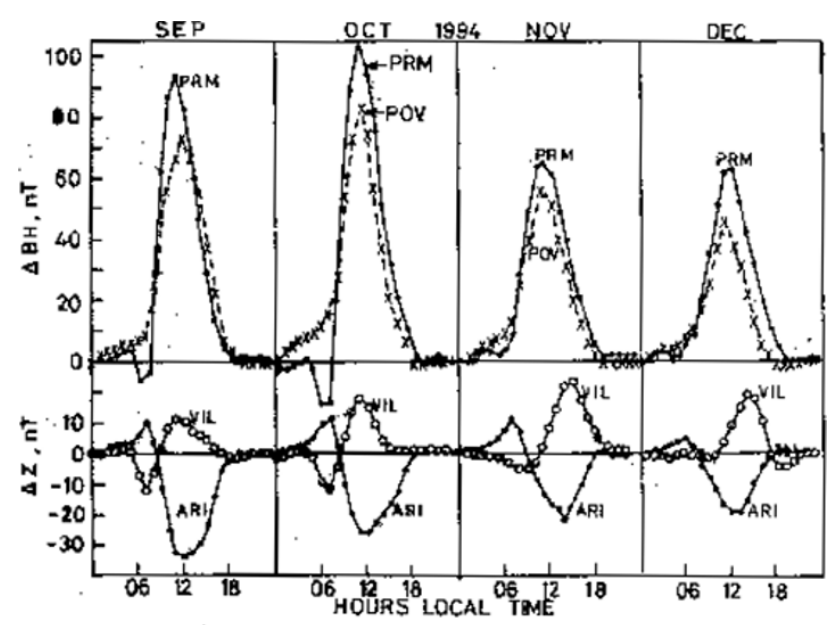

Fig. 9. Monthly mean $S_{\mathrm{q}}$ variations of $B_{H}$ at PRM and POV and of $Z$ at ARI and VIL for September-December 1994.

for all stations. Figure 10 shows the mass plots of $\Delta B_{H}$, $\Delta B_{Y}$ and $\Delta Z$ at each station against the value of $\Delta B_{H}$ at the equatorial station PRM to gain an understanding of the relation of the $B_{H}, B_{Y}$ and $Z$ fields with the strength of the EEJ current on a day-to-day basis.

Figure 10 shows a very high correlation between $\Delta B_{H}$ at POV, VIL and ARI with $\Delta B_{H}$ at PRM, as all these stations are within the EEJ belt. There is a reasonable correlation between $\Delta B_{H}$ at CLB and $\Delta B_{H}$ at PRM, but there is a poor correlation between $\Delta B_{H}$ at PRM and $\Delta B_{H}$ at the off-
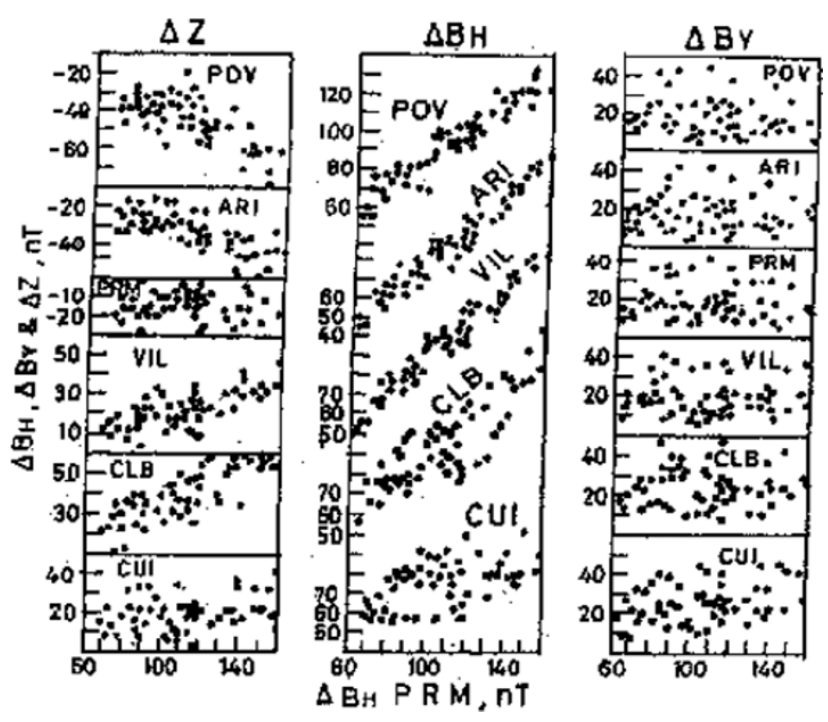

Fig. 10. Mass plots of the daily ranges of the $B_{H}, Z$ and $B_{Y}$ fields at all the six stations in Central Brazil compared with the corresponding values of $\Delta B_{H}$ at the PRM, station close to the centre of the dip equator.

EEJ station CUI. This result suggests that the EEJ current is quasi independent of the global $S_{\mathrm{q}}$ current system, as earlier suggested by James et al. (1996).

With respect to the relation between $\Delta Z$ and $\Delta B_{H}$, there is little correlation between $\Delta Z$ at PRM and $\Delta B_{H}$ at PRM as PRM is very close to the centre of the EEJ and there is very little daily variation in the $Z$ field near the dip equator. 


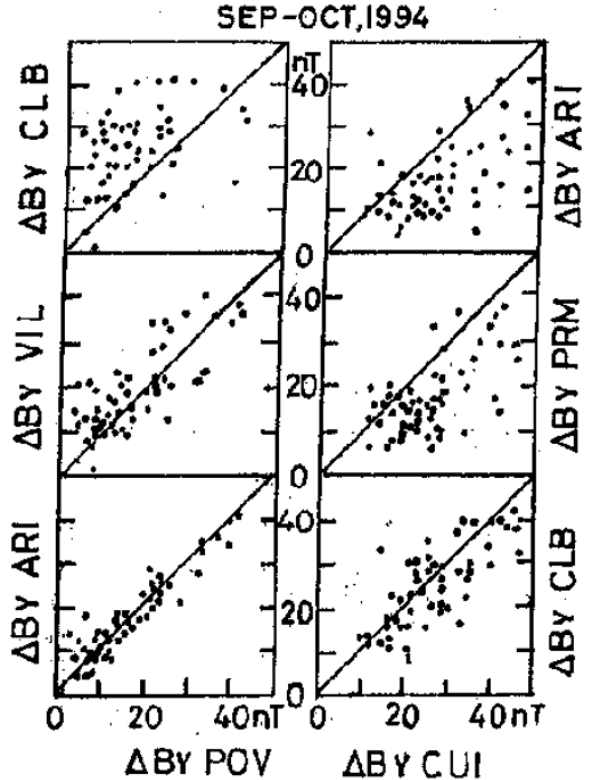

Fig. 11. Mass plots of midday $\triangle B_{Y}$ at VIL and CLB in ARI in relation to the same at POV as well as $\Delta B_{Y}$ at ARI, PRM and CLB in relation to the same at CUI.

At POV and ARI, stations north of magnetic equator, there is an inverse relation between $\Delta Z$ and $\Delta B_{H}$ at PRM, and at the southern stations VIL and CLB, there is a positive correlation between $\Delta Z$ and $\Delta B_{H}$ at PRM. At CUI, station outside the EEJ belt, there is little correlation between $\Delta Z$ and $\Delta B_{H}$ at PRM. These results are consistent with the expectations of the EEJ model-i.e. an increase in the EEJ on a particular day would result in an increase of $Z$ at the southern stations and a decrease of $Z$ at the northern stations in the EEJ belt.

In terms of the relation between $\Delta B_{Y}$ at different stations with $\Delta B_{H}$ at PRM, no correlation can be seen for any of the stations, suggesting that the meridional current causing changes in $\Delta B_{Y}$ is almost independent of the day-to-day variations of $\Delta B_{H}$ at the dip equator.

To isolate the correlation between day-to-day variations of $\Delta B_{Y}$ at the different stations, Fig. 11 was constructed to show the mass plots of the range $B_{Y}$ on individual days at pairs of stations. $\Delta B_{Y}$ at ARI can be seen to be closely related to $\Delta B_{Y}$ at the nearby station POV. The correlation becomes weaker at a station VIL, which is farther from POV, and it is practically absent between CLB and POV. Similarly, the correlations in $\Delta B_{Y}$ between CUI and other stations can be seen to decrease with increasing distance. Thus, there is good correlation between the ranges in $B_{Y}$ at different stations, though not through the changes in the electrojet current strength. The meridional current starts deviating from its original direction with increasing distance.

\subsection{Centre of the equatorial electrojet}

Figure 6 shows that stations VIL and ARI are the most northern and southern stations closest to the dip equator. $\Delta Z$ at noon on a particular day varies linearly with inclination between the stations ARI, PRM and VIL. Thus, these individual day values can be interpolated for the $\Delta Z=0$ intercept on the latitude line, and the centre of the electrojet (a)
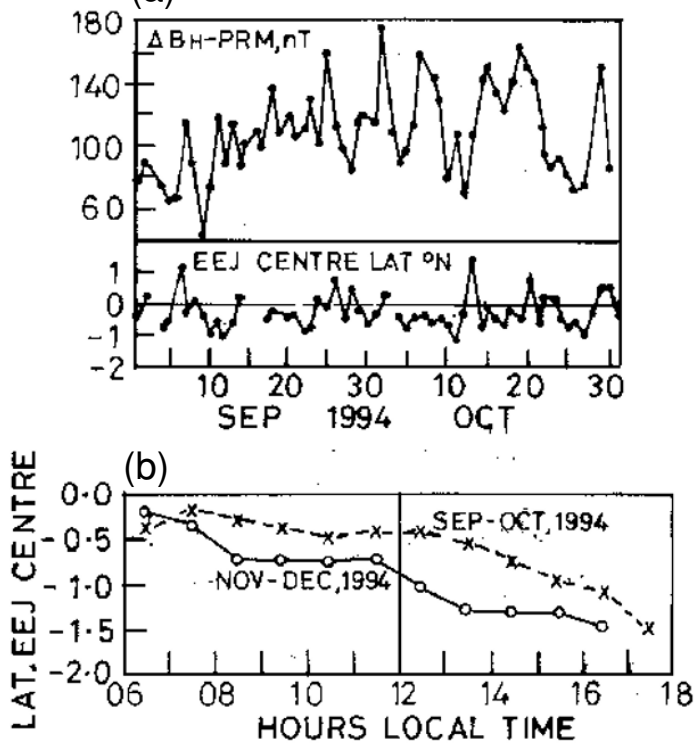

Fig. 12. (a) The day-to-day variation of the centre of the EEJ and its relation with corresponding variation of the EEJ current intensity along Central Brazilian longitude. (b) The variation of the centre of the EJJ current with the local hour along Central Brazilian longitude.

can be computed for each day.

Figure 12(a) shows the latitude of the electrojet centre on each day of September-October 1994. The strength of the electrojet given by $\Delta B_{H}$ at PRM is also plotted to facilitate our study of any correspondence between the strength and centre of the electrojet. On a day-to-day basis, the centre of the electrojet ranges between $\pm 1^{\circ}$ latitude. The median value of the centre of the electrojet was $0.4^{\circ} \mathrm{S}$ of the dip equator. No apparent relation between the strength and the centre of the electrojet could be ascertained.

Figure 12(b) shows the variation of the electrojet centre with local time for the months of September-October and November-December 1994. The electrojet centre was near $-0.25^{\circ}$ dip latitude at the early morning hours and shifted gradually farther from the equator with time, reaching to $-1.5^{\circ}$ by the evening. The typical value of the error bar in the mean value of $\Delta Z$ for the 2 months of data for September-October, as shown in Fig. 6, is about $3 \mathrm{nT}$ at stations close to the centre of the electrojet. This error will amount to an error of $\pm 0.25^{\circ}$ in the estimate of the centre of the dip equator. Thus, the variation shown in Fig. 12(b) is significant. Local time variation of the centre of the EEJ based on ground (Fambitakoye and Mayaud, 1976b) and satellite (Jadhav et al., 2002) data revealed that the centre was closest to the dip equator at noon. Further, the centre of the EEJ was about $0.25-0.5^{\circ}$ further south during November-December 1993 compared to SeptemberOctober 1993. Thus, the centre of the EEJ shows a seasonal shift. Rigoti et al. (1999) found the EEJ centre to be at $21 \pm 16 \mathrm{~km}$ south of the dip equator in the East Brazilian region. Fambitakoye and Mayaud (1976b) found that the centre of the EEJ was about $40 \mathrm{~km}$ north of the dip equator in the longitiude sector of $30^{\circ} \mathrm{E}$. 


\subsection{Magnetic storm effects}

Magnetic storms have a sudden commencement with the arrival of solar plasma ejected from the Sun following solar flares or coronal mass ejection. Continued solar wind pressure causes an increase in the $H$ field at all places until the Interplanetary Magnetic field (IMF) turns southward, when the solar wind magnetic field lines merge with the magnetospheric field lines and the solar plasma makes entry to Earth's magnetic field lines. The solar plasma gets trapped in the Earth's magnetic field lines, causing a westward equatorial ring current, which in turn causes major storm-time decreases in the $H$ field at all stations around the world. Earlier studies did not show any special features of the magnetic storms at EEJ region (Sugiura and Chapman, 1960). Studying the magnetic storm effects in the $H$ field at the chain of 13 stations along Indo-USSR longitudes, Rastogi (1999) showed that the maximum depression in the $H$ field during the main phase showed larger values over the magnetic equator than was expected from the $D_{\text {st }}$ index. Rastogi (2006) recently showed that additional westward electric field is imposed on the equatorial latitudes in the sunlit hemisphere during the storm period when there is steady southward IMF. This additional storm-time effect maximizes over the dip equator at the midday hour sector. The stations in the chain studied here extend on both sides of the dip equator and provide a good opportunity to study the effect of magnetic storms on equatorial electrojet.

Figure 13 shows the variations in the solar wind parameters and ground magnetic field at stations in Central Brazil during 1-3 October 1994 associated with the large magnetic storm. The storm was initiated by the increase of solar plasma ion density from a value of 10 ions per $\mathrm{cm}^{3}$ at $00 \mathrm{LT}$

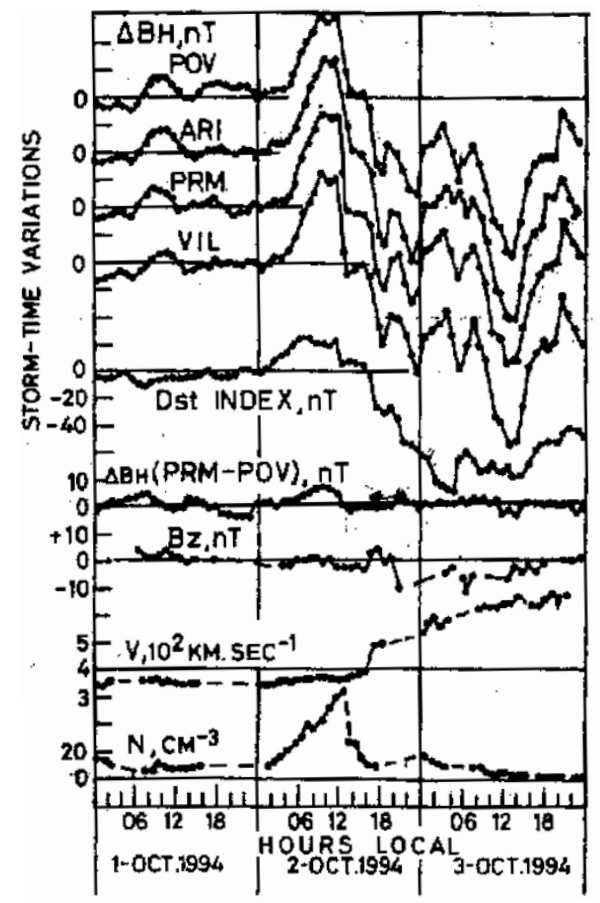

Fig. 13. Storm-time variations in $B_{H}$ at EEJ stations in Central Brazil during the magnetic storm of 2-3 October 1994 along with solar wind parameters. on 2 October 1994 to a value exceeding 60 ions per $\mathrm{cm}^{3}$ at 1200 LT. This caused an increase in the $D_{\text {st }}$ index by more than $20 \mathrm{nT}$, but there was a large $(60 \mathrm{nT})$ increase of $\Delta H$ around the midday hours at all of the stations. There was an increase in the EEJ, as indicated by a positive value of $\Delta H$ (PRM-POV) between 07 and 13 LT. The main phase onset was at 12 LT and was associated with the southward turning of the IMF $B_{z}$ and increase of solar wind velocity. Most of the main phase occurred in the local afternoon and the nighttime hours, and it is to be noted that the storm-time variations of $B_{H}$ were almost similar at all of the stations. $\Delta B_{H}$ (PRM-POV) values were almost zero during the main and recovery phases of the storm.

Thus, the magnetic storms occurring during the local nighttime hours at a particular longitude sector do not have any special effect on the EEJ as it will produce the same effect at low-latitude stations within and outside the EEJ. Therefore, the electrojet strength, as measured by the difference in the $H$ component at the two stations (within and outside electrojet region), remains unaffected. However, if the magnetic storm occurs at local midday hours for a longitude sector, then the depression in the $H$ field is significantly larger at stations within the EEJ belt than at stations at low latitudes outside the electrojet belt.

\section{Conclusion}

This study of the equatorial electrojet (EEJ) in the Central American Sector is based on the analyses of magnetic $B_{H}$, $B_{Y}$ and $Z$ components from six geomagnetic field stations on both sides of the dip equator along $60^{\circ} \mathrm{W}$ geographic longitudes for the period September-October 1994. The following features were apparent.

(1) Geomagnetic field variations in the electrojet region in Central Brazil clearly follow Chapman's model and Baker-Martyn's theory of equatorial electrojet.

(2) The direction of the electrojet current during the midday hours was predominantly in the direction of the magnetic east or along the magnetic equator in this region despite a very large dip declination.

(3) A prominent counter-electrojet were observed around sunrise due to the probable late reversal of the westward nighttime electric field to eastward daytime electric field.

(4) The zonal and meridional components of the ionospheric currents were rather independent of each other.

(5) The centre of the electrojet was at about $0.25^{\circ} \mathrm{S}$ in the morning and shifted to $1.5^{\circ} \mathrm{S}$ by the evening.

(6) The mean strength of the electrojet at $60^{\circ} \mathrm{W}$ longitude was smaller than the corresponding strength of the electrojet at $75^{\circ} \mathrm{W}$ longitude.

(7) The magnetic storm during the midday hours showed an abnormally larger depression in $H$ at stations close to the dip equator.

Acknowledgments. The chain of equatorial stations in the Central America were initially installed by Prof. Tai-ichi Kitamura and are presently organized by Prof. K. Yumoto. Hourly mean values of data were computed by Kentarou Kitamura. Further data analyses were carried out at the Physical Research Laboratory and Gujarat University at Ahmedabad, India with financial assistance from Indian Space Research Organisation, India. 


\section{References}

Arora, B. R., M. V. Mahashabde, and R. Kalra, Indian IEEY geomagnetic observational program and some preliminary results, Rev. Braz. Geofis., 11, 365-385, 1993.

Baker, W. G. and D. F. Martyn, Electric currents in the ionosphere. The conductivity, Philos. Trans. R. Soc. Lond., A246, 281-294, 1953.

Chapman, S., The equatorial electrojet as detected from the abnormal electric current distribution above Huancayo, Peru and elsewhere, Arch. Meterol. Geophys. Bioklimatol, A4, 368-390, 1951.

Chapman, S. and K. S. Rajarao, The $\mathrm{H}$ and $\mathrm{Z}$ variations along and near the equatorial electrojet in India, Africa and Pacifics, J. Atmos. Terr. Phys., 27, 559-581, 1965.

Doumouya, V., J. Vassal, Y. Cohen, O. Fambitakoye, and M. Menvielle, Equatorial electrojet at African longitudes: first results from magnetic measurements, Ann. Geophys., 16, 658-676, 1998.

Fambitakoye, O. and P. N. Mayaud, Equatorial electrojet and regular daily variations of SR-I. A determination of the equatorial electrojet parameters, J. Atmos. Terres. Phys., 38, 1-17, 1976a.

Fambitakoye, O. and P. N. Mayaud, Equatorial electrojet and regular daily variations SR-II. The Centre of the equatorial electrojet, J. Atmos Terres. Phys., 38, 19-26, 1976b.

Forbush, S. and M. Casaverde, Equatorial electrojet in Peru, Carnegie Institution of Washington Report No.620, 1961.

Godivier, R. and Y. Grenn, Equatorial electrojet in Chad, Ann. Geophys., 21, 143-155, 1965.

Hesse, D., An investigation of the equatorial electrojet by means of the ground based magnetic measurements in Brazil, Ann. Geophys., 38, 315-320, 1982.
Jadhav, G., M. Rajaram, and R. Rajaram, A detailed study of equatorial electrojet phenomenon using Orsted satellite observations, J. Geophys. Res., 107(A8), 1175, doi:10.1029, 2001JA000183, 2002.

James, M. E., D. Tripathi, and R. G. Rastogi, Day-to-day variability of ionospheric current system, Ind. J. Radio Space Phys., 25, 36-43, 1996.

Rastogi, R. G., Longitudinal variation in the equatorial electrojet, J. Atmos. Terr. Phys., 24, 1031-1040, 1962.

Rastogi, R. G., Geomagnetic storm effects at low latitudes, Ann. Geophys., 17, 438-444, 1999.

Rastogi, R. G., A new look at the ionospheric current system during IGY period, Ind. J. Rad. Space Phys., 32, 21-37, 2003.

Rastogi, R. G., Magnetic storm effects at equatorial electrojet stations, Earth Planets Space, 58, 645-657, 2006.

Rastogi, R. G. and K. N. Iyer, Quiet day variation of geomagnetic H field at low latitudes, J. Geomag. Geoelecr., 36, 377-379, 1976.

Rastogi, R. G. and R. J. Stening, On the eastward geomagnetic field variations of electrojet stations, Ind. J. Rad. Space Phys., 31, 67-74, 2002.

Rigoti, A., F. H. Chamalan, N. B. Trivedi, and A. L. Padilha, Characteristics of the equatorial electrojet determined from an array of magnetometers in N-NE Brazil, Earth Planets Space, 51, 115-128, 1999.

Sugiura, M. and S. Chapman, The average morphology of the geomagnetic storms with sudden commencement, Abh. Akad. Wiss. Gottingen. Math. Phys. Klass Sonderreft, Nr 4, 1-53, 1960.

R. G. Rastogi, H. Chandra (e-mail: hchandra@prl.res.in), M. E. James, K. Kitamura, and K. Yumoto 